Objectives: To define the prevalence of PHP in patients with RA.

Methods: All RA patients who were registered in the local part of Danish Danbio registry were included in this study. Patients'demographic data and serology results (rheumatoid factor (RF) and anti-cyclic citrullinated peptide antibody (anticcp)) were extracted from Danbio. Patients' electronic hospital records including laboratory results (Parathyroid hormone (PTH) and calcium levels) were reviewed to reveal if they had been diagnosed with PHP as well.

Results: 1035 RA patients were included in this study [table 1]. Prevalence of PHP was 2.8\% (29/1035). RA Patients with PHP had significant longer disease duration compared to patients with isolated RA ( $p=0.003)$. There was no significant difference between RA patients with and without PHP with respect to age, gender, RF and anti-ccp positivity (Table 1).

Table 1. Association of PHP with age, gender, disease duration, Rheumatoid Factor and Anti-ccp in RA patients

\begin{tabular}{lccc}
\hline Variables: & $\begin{array}{c}\text { RA patients with PHP } \\
\mathrm{N}=29\end{array}$ & $\begin{array}{c}\text { RA patients without PHP } \\
\mathrm{N}=1006\end{array}$ & P value \\
\hline Age & $69.9 \pm 10.6$ & $67.0 \pm 14.6$ & \\
Gender, Female & $23(79.3 \%)$ & $633(62.9 \%)$ & 0.170 \\
Disease Duration & $15.2 \pm 9.5$ & $9.4 \pm 9.6$ & 0.107 \\
Rheumatoid Factor, Positive & $20(69 \%)$ & $587(58.3 \%)$ & 0.003 \\
Anti-ccp, Positive & $19(65.6 \%)$ & $513(51 \%)$ & 0.393 \\
\hline RA: & &
\end{tabular}

RA: Rheumatoid Arthritis, PHP: Primary Hyperparathyroidism.

Conclusions: Clinicians should pay special attention to higher prevalence of PHP among RA patients compared to the general population. Presence of PHP in RA patients may aggravate the effect of RA on bones and joints by means of interaction with cytokines and inflammatory markers involved in RA. Concurrent PHP can be diagnosed at early stage by testing PTH and calcium levels which minimize the future morbidities e.g. fracture due to osteoporosis.

References:

[1] Dougados M, Soubrier M, Antunez A, et al. Prevalence of comorbidities in rheumatoid arthritis and evaluation of their monitoring: results of an international, cross-sectional study (COMORA). Ann Rheum Dis 2014;73:628.

[2] Yeh MW, Ituarte PH, Zhou HC, et al. Incidence and prevalence of primary hyperparathyroidism in a racially mixed population. J Clin Endocrinol Metab 2013;98:1122-9.

Acknowledgements: We thank Mrs. Maryam Mousavi for her contribution to data collection.

Disclosure of Interest: None declared

DOI: 10.1136/annrheumdis-2017-eular.5304

\section{FRI0140 COMORBIDITY AND SURGERY HISTORY OF RHEUMATOID ARTHRITIS PATIENTS WHO ARE RECEIVING BIOLOGICAL AGENT}

B. Armagan ${ }^{1}$, A. Sari ${ }^{1}$, A. Erden ${ }^{1}$, L. Kilic ${ }^{1}$, E.C. Erdat ${ }^{2}$, O. Karadag ${ }^{1}$, A. Akdogan ${ }^{1}$, S. Apras Bilgen ${ }^{1}$, U. Kalyoncu ${ }^{1}$, I. Ertenli ${ }^{1}$, S. Kiraz ${ }^{1} .{ }^{1}$ Hacettepe University, Department of Internal Medicine, Division of Rheumatology;

${ }^{2}$ Department of Internal Medicine, Hacettepe University, Ankara, Turkey

Background: Rheumatoid artritis (RA) is a chronic and autoimmune disorder that primarily affects middle and older ages. Comorbidities are important during RA treatment.

Objectives: We aim to determine the frequency of comorbidites and surgical history in the RA patients who receive biological agents.

Methods: Hacettepe University Biologic Registry (HUR-BIO) includes demographic and clinical data of patients treated with biological agent since 2005. By August 2016, 1235 RA patients were recorded in the database. Age, gender, smoking habits, disease duration, rheumatoid factor, anti citrullinated peptide (CCP), C-reactive protein (CRP), erythrocyte sedimentation rate (ESR), current and previous treatments, comorbidites and surgical history of patients were analyzed. Comorbidites and surgery history were determined by patients medical records. Disease activity was estimated by the 28-joint activity calculator- $\mathrm{C}$ reactive protein (DAS28-CRP). Functional assessment was evaluated by the Health Assessment Questionnaire (HAQ).

Results: Mean age (SD) of the patients $(79,8 \%$ women) was $53,1(12,6)$ and the mean disease duration was $11,0(7,7)$ years. Of patients, $166(16,6 \%)$ were older than 65 years. A total of $630(63 \%)$ patients education level were less than high school, $197(19,7 \%)$ of the patients were graduated from university. Smoking habitus of patients was as follows, $599(59,9 \%)$ never smoked, $189(18,9 \%)$ current smoker and $212(21,2 \%)$ ex-smoker. At least one cardiovascular risk factor was detected in $699(69,9 \%)$ patients. Comorbidities and surgical history of patients were shown in the table below. Patients with at least one comorbidity had less frequently female $(77.3 \%$ vs $84.5 \%, p=0.007)$, high seropositivitly of RF ( $66 \%$ vs $57.1 \%, p=0.004)$, high patient global assessment $(4.4 \pm 2.5$ vs $3.9 \pm 3.9$, $p=0.007)$, high fatique score $(4.6 \pm 3$ vs $3.9 \pm 3.1, p=0.001)$, high pain score $(4.8 \pm 2.5$ vs $4.0 \pm 2.8, \mathrm{p}=0.009)$, DAS- $28(3.43 \pm 1.39$ vs $3.17 \pm 1.48, \mathrm{p}=0,009)$ and high $\mathrm{HAQ}$ score $(0.72 \pm 0.59$ vs $0.58 \pm 0.54, p=0.001)$ than patients without comorbidities. Conclusions: Comorbidities and past surgical history should be considered in RA patients when biological therapy is indicated. Comorbidities is one of the important conditions for physicians to manage patients. Cardiovascular, chronic viral infection such as hepatitis B and C, tuberculosis and cancer have to be

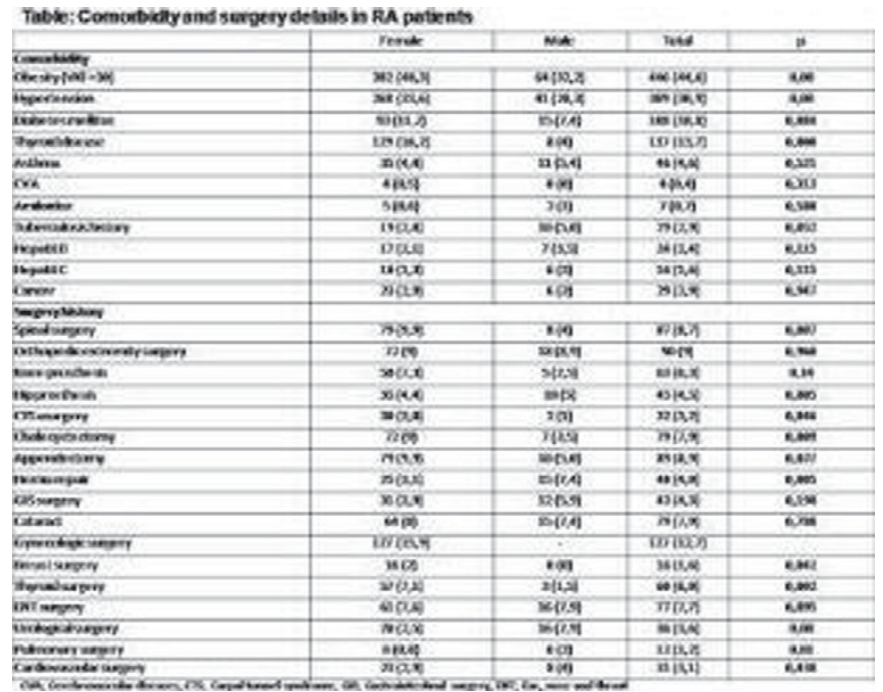

investigated to start biological treatments. Surgical history such as cataracts, ortopedic surgery were also important for clinicians. HURBIO data demonstrated that patients with at least one comorbidities reflects more negative patient outcome measures.

Disclosure of Interest: None declared

DOI: 10.1136/annrheumdis-2017-eular.4282

\section{FRI0141 LEFT VENTRICULAR CONCENTRIC REMODELING IS MORE PREVALENT IN RHEUMATOID ARTHRITIS: A CASE-CONTROL STUDY}

D.Á. Galarza-Delgado ${ }^{1}$, J.R. Azpiri-López ${ }^{2}$, I.J. Colunga-Pedraza ${ }^{1}$,

F.J. Torres-Quintanilla ${ }^{2}$, R.E. Ramos-Cázares ${ }^{1}$, A. Valdovinos-Bañuelos ${ }^{1}$,

A. Martínez-Moreno ${ }^{3}$, R.I. Arvizu-Rivera ${ }^{3}$, R. Vera-Pineda ${ }^{3}$, J.A. Cárdenas-de la Garza $^{3}$, M.A. Garza-Elizondo ${ }^{1}$, M.A. Benavides-González ${ }^{2}$, J.A. Silva-Ortiz ${ }^{2}$.

${ }^{1}$ Rheumatology; ${ }^{2}$ Cardiology; ${ }^{3}$ Internal Medicine, Hospital Universitario "Dr. José Eleuterio González", UANL, Monterrey, Mexico

Background: Patients with rheumatoid arthritis (RA) have a higher risk to develop cardiovascular complications than general population (1), leading to a decrease in life expectancy of 3 to 10 years (2). RA is associated to increased left ventricle mass, pericardial effusion and diastolic dysfunction (3).

Objectives: The aim of this study was to assess the structure and function of the left ventricle in patients with RA and compare the results with matched controls.

Methods: We designed an observational cross-section case-control study. Patients diagnosed with RA according to the 1987 ACR and/or 2010 ACR/EULAR classification criteria, 40-75 years old, with no overlap syndromes, atherosclerotic cardiovascular disease or hypertension were included. Subjects for the control group were matched by sex, age and comorbidities. A board-certified cardiologist performed a transthoracic echocardiogram.

Results: We included a total of 44 RA-patients and 26 control subjects. Table 1 summarizes the demographic characteristics for each group. Left ventricular concentric remodeling (LVCR), defined as a relative wall thickness (RWT) $>0.42$ $\mathrm{cm}$ and a left ventricular mass index $\left(\right.$ LVMI) $\leq 95 \mathrm{gm} / \mathrm{m}^{2}$ in women and $\leq 115$ $\mathrm{gm} / \mathrm{m}^{2}$ in men, was found in 14 patients $(32.6 \%)$ of the RA-group and 2 subjects $(8 \%)$ of the control group; this difference was statistically significant $(p=0.021)$.

When we analyzed general abnormalities of left ventricle (either LVCR or left ventricular concentric hypertrophy [RWT $>0.42 \mathrm{~cm}$ and LVMI $>95 \mathrm{gm} / \mathrm{m}^{2}$ in women, $>115 \mathrm{gm} / \mathrm{m}^{2}$ in men]) we found 15 RA patients (34.1\%) with abnormalities and 3 subjects in the control group (11.5\%) $(p=0.037)$. There were no statistically significant differences among the groups in LVMI, diastolic dysfunction, global longitudinal strain or ejection fraction.

Table 1. Demographic characteristics

\begin{tabular}{lccc}
\hline & RA group $(\mathrm{n}=44)$ & Control group $(\mathrm{n}=26)$ & $p$ \\
\hline Age, mean \pm SD & $52.35 \pm 7.34$ & $53.94 \pm 6.81$ & 0.371 \\
Disease duration (years), mean \pm SD & $10.682 \pm 8.3321$ & - & - \\
DAS-28 CRP, mean \pm SD & $3.36 \pm 1.42$ & - & - \\
Women, $\mathrm{n}(\%)$ & $43(97.7)$ & $24(92.3)$ & 0.279 \\
Body Mass Index, mean \pm SD & $26.98 \pm 6.13$ & $28.3 \pm 4.12$ & 0.956 \\
Active smoking, $\mathrm{n}(\%)$ & $4(9.1)$ & $0(0)$ & 0.113 \\
Type 2 Diabetes mellitus, $\mathrm{n}(\%)$ & $2(4.5)$ & $2(7.7)$ & 0.584 \\
\hline
\end{tabular}

DAS-28 CRP - Disease activity score 28 using C-reactive protein.

Conclusions: Left ventricle concentric remodeling is more prevalent in RApatients when compared to controls. Further research is needed to determine the impact of these findings in the clinical prognosis of RA-patients.

References:

[1] Solomon DH, Curhan GC, Rimm EB, Cannuscio CC, Karlson EW. Cardiovas- 
Table 2

\begin{tabular}{lccc}
\hline & $\begin{array}{c}\text { RA group } \\
(\mathbf{n = 4 4 )}\end{array}$ & $\begin{array}{c}\text { Control group } \\
(\mathbf{n = 2 6 )}\end{array}$ & $\boldsymbol{p}$ \\
\hline LVCR, $\mathbf{n}(\%)$ & $14(32.6)$ & $2(8)$ & $\underline{\mathbf{0 . 0 2 1}}$ \\
LVCR or LVH, $\mathbf{n}(\%)$ & $15(34.1)$ & $3(11.5)$ & $\underline{\mathbf{0 . 0 3 7}}$ \\
$\begin{array}{l}\text { Diastolic dysfunction, } \\
\mathbf{n}(\%)\end{array}$ & $20(45.5)$ & $9(34.6)$ & 0.374 \\
$\begin{array}{l}\text { Left ventricular mass } \\
\text { index }\left(\mathbf{g} / \mathbf{m}^{2}\right), \text { mean } \pm\end{array}$ & $66.77 \pm 17.11$ & $68.65 \pm 18.31$ & 0.668 \\
SD & & & \\
EF $(\%)$, mean \pm SD & $60.85 \pm 4.94$ & $62.62 \pm 6.67$ & 0.228 \\
GLS $(\%)$ mean \pm SD & $-20.66 \pm 2.63$ & $-21.6 \pm 2.52$ & 0.189 \\
$\begin{array}{l}\text { TAPSE }(\mathbf{m m}), \text { mean } \pm \\
\text { SD }\end{array}$ & $23.23 \pm 4.34$ & $23.84 \pm 2.71$ & 0.485 \\
\hline LVCR - Left ventricular concentric remodeling, LVH - Left ventricular hypertrophy,
\end{tabular}

GLS - Global longitudinal strain, TAPSE - Tricuspid annular plane systolic excursion.

cular risk factors in women with and without rheumatoid arthritis. Arthritis \& Rheumatism. 2004;50(11):3444-9.

[2] Myasoedova E, Davis JM, Crowson CS, Gabriel SE. Epidemiology of Rheumatoid Arthritis: Rheumatoid Arthritis and Mortality. Current Rheumatology Reports. 2010;12(5):379-85.

[3] Corrao S, Messina S, Pistone G, Calvo L, Scaglione R, Licata G. Heart involvement in Rheumatoid Arthritis: Systematic review and meta-analysis. International Journal of Cardiology. 2013;167(5):2031-8.

Disclosure of Interest: None declared

DOI: 10.1136/annrheumdis-2017-eular.5623

\section{FRI0142 NEUTROPENIA IN RHEUMATOID ARTHRITIS. INCIDENCE,} PROGNOSTIC FACTORS, NATURAL HISTORY AND OUTCOME

G.E. Fragoulis $^{1}$, I.B. McInnes ${ }^{1}$, D. Porter ${ }^{2}$, S. Siebert ${ }^{1}$ on behalf of SERA collaborators. ${ }^{1}$ Institute of Infection, Immunity and Inflammation, University of Glasgow; ${ }^{2}$ Rheumatology, NHS Greater Glasgow and Clyde, Glasgow, United Kingdom

Background: Neutropenia is an uncommon finding in the context of rheumatoid arthritis (RA). The incidence and association with RA features is not yet well-defined.

Objectives: To determine the incidence and severity of neutropenia in an early RA inception cohort, explore possible association with RA features and describe its impact on patient's management.

Methods: The Scottish Early Rheumatoid Arthritis (SERA) inception cohort prospectively recruited newly diagnosed RA patients (ACR-EULAR 2010 criteria), who were followed-up every 6 months. Patients who developed at least one episode of neutropenia (grade $1:<2000 / \mu \mathrm{L}$, grade $2:<1500 / \mu \mathrm{L}$, grade 3 : $<1000 / \mu \mathrm{L}$, grade $4:<500 / \mu \mathrm{L}$ ) were compared with patients who never developed neutropenia. Binominal logistic regression was performed, exploiting the enter model and using the occurrence of neutropenia as dependent variable.

Results: 77 episodes of neutropenia were observed in $60(8.6 \%)$ out of 698 RA patients, who were followed up for a median (range) time of 18 (6-48) months. Neutropenia occured in $12(0-120)$ [median (range)] months after RA diagnosis. The majority had mild neutropenia (grade $1: n=49$, grade $2: n=9$, grade $3: n=0$, grade $4: n=2$ ) and the mean $\pm S D$ number of neutrophils/ $\mu L$ was $1.68 \pm 0.35$. Of the 77 neutropenic episodes recorded, coexistent lymphopenia was found in $13.0 \%$, leukopenia in $70.1 \%$, thrombocytopenia in $1.3 \%$ and anaemia in $32.5 \%$. At the time of the neutropenia, most of the patients were in remission (DAS28<2.6: $53 \%$, DAS $28<3.2: 15.5 \%$, DAS $28 \leq 5.1: 22.4 \%$, DAS $28>5.1: 8.6 \%)$. Neutropenia was a single episode in the majority $(76.7 \%)$ of the patients and led to treatment discontinuation in $11.7 \%$ of them.

Patients who subsequently developed neutropenia, were more likely females $(p=0.03)$ and non-smokers $(p=0.0009)$ (Table 1). Treatment received for RA was comparable between the two groups. Binominal regression analysis confirmed female gender $[p=0.017, \operatorname{Exp}(B): 2.587]$ and not smoking $[p=0.032, \operatorname{Exp}(B): 2.880]$ as predictors of neutropenia development.

During total follow-up time, patients who had at least one episode of neutropenia they also manifested more commonly anaemia $(p=0.04)$ and lymphopenia

Table 1. Baseline patients characteristics

\begin{tabular}{|c|c|c|c|}
\hline & Neutropenia & No Neutropenia & $\mathrm{p}$ value \\
\hline Patients characteristics & $\mathrm{N}=60$ & $\mathrm{~N}=638$ & \\
\hline Age, mean (mean $\pm S D)$ & $58.7 \pm 14.5$ & $58.7 \pm 13.2$ & 0.978 \\
\hline Female gender, No (\%) & $50(83.3 \%)$ & $414(64.9 \%)$ & 0.03 \\
\hline Total follow-up (months), median (range) & $18(6-48)$ & $18(6-48)$ & 0.173 \\
\hline Smoking, No (\%) & $5(8.3)$ & $172(27.0)$ & 0.0009 \\
\hline Smoking (present/past/never) & $5 / 23 / 32$ & $172 / 240 / 225$ & 0.002 \\
\hline Anaemia $^{a}$, No (\%) & $8 / 57(14.0)$ & $133 / 631(21.1)$ & 0.235 \\
\hline Thrombocytopenia $^{\mathrm{b}}$, No (\%) & $0 / 57(0.0)$ & $0 / 631(0.0)$ & 1.000 \\
\hline Leukopeniac ${ }^{c}$, No $(\%)$ & $1 / 57(1.7)$ & $3 / 631(0.4)$ & 0.293 \\
\hline Lymphopenia $^{\mathrm{d}}$, No (\%) & $4(7.0)$ & $34 / 631(5.4)$ & 0.545 \\
\hline RF positive, No (\%) & $28 / 36(77.8)$ & $295 / 401(73.5)$ & 0.693 \\
\hline Anti-CCP positive, No (\%) & $34 / 48(70.8)$ & $410 / 527(77.8)$ & 0.282 \\
\hline Baseline DAS28 (mean $\pm S D$ ) & $4.8 \pm 1.6$ & $5.02 \pm 1.42$ & 0.408 \\
\hline
\end{tabular}

${ }^{a} \mathrm{Hb}<120 \mathrm{~g} / \mathrm{L}$, ${ }^{b}$ platelets $<100000 / \mu \mathrm{l}$, ${ }^{\mathrm{c}}$ white blood cells: $<4 \times 10^{9} / \mathrm{L}$, dymphocytes: $<1 \times 10^{9} / \mathrm{L}$. $(p=0.03)$. The rate of infections $/ 1000$ person-months did not differ between patients who developed neutropenia and those who did not [5.75 (2.47-11.33) vs 4.1 (3.13-5.47), $p=0.399]$

Conclusions: Neutropenia was observed in about $9 \%$ of patients in this early RA cohort. It was usually mild, transient and not associated with increased infection rates. Interestingly, not-smoking and female gender were associated with neutropenia.

Disclosure of Interest: None declared

DOI: 10.1136/annrheumdis-2017-eular.6725

\section{FRI0143 PREVALENCE AND DETERMINANTS OF PERIPHERAL ENDOTHELIAL DYSFUNCTION IN A COHORT OF RHEUMATOID ARTHRITIS PATIENTS: PRELIMINARY RESULTS FROM A MULTICENTER CROSS-SECTIONAL STUDY}

G.L. Erre ${ }^{1,1}$, M. Piga $^{2}$, A.L. Fedele ${ }^{3}$, M.L. Cadoni ${ }^{1}$, G. Di Sante ${ }^{3}$, I. Cangemi $^{2}$, A. Piras ${ }^{4}$, M. Dessì ${ }^{2}$, S. Mura ${ }^{4}$, B. Tolusso ${ }^{3}$, M.G. Longu ${ }^{1}$, P.S. Saba ${ }^{5}$, E. Gremese ${ }^{3}$, A. Cauli ${ }^{2}$, G. Ferraccioli ${ }^{3}$, A. Mathieu ${ }^{2}$, G. Passiu ${ }^{4} .{ }^{1}$ UOC Reumatologia, Dipartimento di Medicina Clinica e Sperimentale, Azienda Ospedaliero-Universitaria di Sassari, Sassari; ${ }^{2}$ UOC Reumatologia, Azienda Ospedaliero-Universitaria di Cagliari, Cagliari; ${ }^{3}$ UOC Reumatologia, Policlinico Gemelli, Roma; ${ }^{4}$ UOC Reumatologia, Dipartimento di Medicina Clinica e Sperimentale, Università degli Studi di Sassari; ${ }^{5}$ UO Cardiologia, Azienda Ospedaliero-Universitaria di Sassari, Sassari, Italy

Background: RA patients suffer of a life expectancy significantly reduced with respect to the general population mainly due to cardiovascular (CV) disease. Endothelial dysfunction (ED), the early step in atherosclerotic process, is more evident in RA than in the general population. Peripheral arterial tonometry (PAT), a simple, rapid, and objective tool for evaluation of ED, measures small digital artery reactive hyperaemia after an ischemic stimulus in forearm. PAT shows high grade of correlation with coronary ED and predicts future CV events in the general population.

Objectives: To define prevalence and determinants of peripheral ED in RA.

Methods: Data from 633 RA patients free of previous CV events prospectivelly enrolled in the EDRA study* (ClinicalTrials.gov: NCT02341066) were analysed. Reactive hyperemia index (LnRHI) was evaluated by PAT using the EndoPAT2000 device: ED was defined by $\mathrm{LnRHI}<0.51$. Linear and logistic regression analysis were performed to define independent predictors of ED in RA patients. A p-value $<0.05$ was considered statistically significant.

Results: Peripheral ED was documented in 212 out of 633 RA patients (33.3\%). A linear regression for multiple variables (stepwise method) performed including into the models variables showing significant association with $\mathrm{LnRHI}$ at the univariate regression analysis (systolic blood pressure, HDL cholesterol levels, triglycerides levels, smoking habit and ACPA positivity; Age and gender were forced) showed that only higher levels of triglycerides [B coefficient $(95 \% \mathrm{IC})=-0,001(-0,001-$ $0,00) ; p<0.05]$ negativity for ACPA [B coefficient $(95 \% \mathrm{IC})=-0,070(-0,135-0,005)$; $p<0.05$ ] and smoking habit [B coefficient $(95 \% \mathrm{IC})=0,01(0,043-0,156) ; p<0.05]$ were independently related to lower values of $\mathrm{LnRHI}$. No significant correlation between peripheral ED and RA activity (DAS-28, CDAI, SDAI, HAQ), burden of systemic inflammation (CRP, ESR) and type of immunosuppressive treatment (steroids, NSAIDs, DMARDs and bDMARDs) was found. At logistic regression analysis ACPA negativity [OR $((95 \% \mathrm{IC})=1.57(1.04-2.21) ; p<0.05]$ and smoking habit [OR $((95 \% \mathrm{IC})=1.64(1.06-2.53) ; p<0.05]$ indipendently conferred a major risk of peripheral ED.

Conclusions: This study demonstrates for the first time a very high prevalence of peripheral ED in patient with RA free of previous CV events. Triglycerides levels and smoking habit, among traditional cardiovascular risk factor, showed a significant correlation with lower peripheral ED. Surprisingly ACPA negativity confers an increased risk for ED in RA population. Moreover, other than expected, systemic inflammation does not appear to influence peripheral ED in RA population. In conclusion our data further support the notion that atherogenesis in RA is only partially driven by traditional CV factors. The negative association between ACPA and ED warrants further investigation.

Acknowledgements: *The EDRA study is a project funded by Italian Ministry of Health and by Regione Sardegna (RAS) (GR-2011-02352816; Ricerca Finalizzata 2011).

Disclosure of Interest: None declared

DOI: 10.1136/annrheumdis-2017-eular.2234

\section{FRI0144 EVALUATION OF FACTORS AFFECTING FATIGUE IN PATIENTS WITH RHEUMATOID ARTHRITIS}

G. Kilinc Kamaci ${ }^{1}$, S. Unsal Delialioglu ${ }^{1}$, S. Ozel ${ }^{1}$, F. Yurdakul ${ }^{2}$, H. Bodur ${ }^{2}$.

${ }^{1}$ Ankara Physical Therapy and Rehabilitation Training and Research Hospital;

${ }^{2}$ Ankara Numune Training and Research Hospital, Ankara, Turkey

Background: Fatigue is a common and disturbing symptom in patients with Rheumatoid arthritis (RA) $(1,2)$. Measuring fatigue, understanding its contributory factors, and treating it lead to better patient outcome (3).

Objectives: The aim of this study is to investigate the relation between fatigue and pain, functional status, disease activity in patients with RA and to determine the effect of fatigue on the quality of life of patients with RA. 